\title{
Administration of the phosphodiesterase type 4 inhibitor rolipram into the amygdala at a specific time interval after learning increases recognition memory persistence
}

\author{
Aline Werenicz, ${ }^{1,2,3}$ Raissa R. Christoff, ${ }^{1,2,3}$ Martina Blank, ${ }^{1,2,3}$ Paulo F.C. Jobim, ${ }^{1,2,3}$ \\ Thiago R. Pedroso, ${ }^{1,2,3}$ Gustavo K. Reolon, 1,2,3 Nadja Schröder, ${ }^{3,4}$ and \\ Rafael Roesler ${ }^{1,2,3,5}$
}

${ }^{1}$ Laboratory of Neuropharmacology and Neural Tumor Biology, Department of Pharmacology, Institute for Basic Health Sciences, Federal University of Rio Grande do Sul, 90050-170 Porto Alegre, RS, Brazil; ${ }^{2}$ Cancer Research Laboratory, University Hospital Research Center (CPE-HCPA), Federal University of Rio Grande do Sul, 90035-003 Porto Alegre, Brazil; ${ }^{3}$ National Institute for Translational Medicine (INCT-TM), 90035-003 Porto Alegre, Brazil; ${ }^{4}$ Neurobiology and Developmental Biology Laboratory, Faculty of Biosciences, Pontifical Catholic University, $90619-900$ Porto Alegre, RS, Brazil

\begin{abstract}
Here we show that administration of the phosphodiesterase type 4 (PDE4) inhibitor rolipram into the basolateral complex of the amygdala (BLA) at a specific time interval after training enhances memory consolidation and induces memory persistence for novel object recognition (NOR) in rats. Intra-BLA infusion of rolipram immediately, $1.5 \mathrm{~h}$, or $6 \mathrm{~h}$ after training had no effect on retention tested at 1,7 , and $14 \mathrm{~d}$ later. However, rolipram infused $3 \mathrm{~h}$ post-training promoted memory persistence for up to at least $14 \mathrm{~d}$. The findings suggest that PDE4 inhibition in the BLA can enhance long-term memory formation when induced specifically $3 \mathrm{~h}$ after learning.
\end{abstract}

\begin{abstract}
The basolateral complex of the amygdala (BLA) is involved in enhancing the consolidation of memories for emotionally arousing events (for review, see McGaugh 2004). Recent evidence suggests that the BLA may also modulate memories for low-arousing tasks, including novel object recognition (NOR), a task based on the natural preference toward novel objects displayed by rats and mice (Roozendaal et al. 2006, 2008; Okuda et al. 2004).

Phosphodiesterase type 4 (PDE4), an enzyme that catalyzes hydrolysis of cAMP, plays a critical role in regulating the activity of protein kinase A (PKA). The cAMP/PKA/cAMP regulatory element-binding protein (CREB) signaling pathway in the BLA is involved in regulating memory for fear-motivated tasks (Schafe and LeDoux 2000; Roozendaal et al. 2002). The specific PDE4 inhibitor rolipram enhances synaptic plasticity and memory formation in rodents, particularly when animals are given a mild training, and also ameliorates memory deficits in models of cognitive impairment (Barad et al. 1998; Bourtchouladze et al. 2003; Rutten et al. 2006; for review, see Tully et al. 2003). However, to our knowledge previous studies have not verified whether PDE4 inhibitors affect memory when given into the amygdala. Moreover, although systemic administration of rolipram has been shown to rescue deficits in rat and mouse models of memory dysfunction (Bourtchouladze et al. 2003; Rutten et al. 2006; de Lima et al. 2008), the possible effects of amygdalar PDE4 inhibition on NOR memory have not been investigated. In this study, we examined the effects of administration of rolipram into the BLA at different time intervals after training on long-term retention of NOR memory in rats.
\end{abstract}

\footnotetext{
${ }^{5}$ Corresponding author

E-mail rafael.roesler@pq.cnpq.br

Article is online at http://www.learnmem.org/cgi/doi/10.1101/lm.026997.112.
}

Male adult Wistar rats (age 3-4 mo; weight 270-330 g) were obtained from our institutional breeding colony (CREAL-UFRGS). The animals were housed five to a plastic cage with sawdust bedding and were maintained on a 12-h light:12-h dark cycle (lights on at 7 a.m.) with room temperature of $22 \pm 1{ }^{\circ} \mathrm{C}$. Food and water were available ad libitum. Behavioral procedures were conducted between 9 a.m. and 7 p.m. All experimental procedures were performed in accordance with the NIH Guide for the Care and Use of Laboratory Animals (NIH publication number 80-23, revised 1996) and approved by the institutional animal care committee under protocol number 10-0552.

Animals were bilaterally implanted under ketamine $(75 \mathrm{mg} /$ $\mathrm{kg})$ and xylazine $(25 \mathrm{mg} / \mathrm{kg})$ with a $14.0-\mathrm{mm}, 22$-gauge guide cannula aimed $1.0 \mathrm{~mm}$ above the BLA (Roesler et al. 2003, 2004b). Stereotaxic coordinates were according to the atlas of Paxinos and Watson (2007): A $2.8 \mathrm{~mm}, \mathrm{~L} \pm 4.8 \mathrm{~mm}, \mathrm{~V} 7.5 \mathrm{~mm}$. Rats given at least $5 \mathrm{~d}$ to recover before the experimental procedures.

NOR training and testing was conducted in a $40-\mathrm{cm} \times 50-\mathrm{cm}$ open field surrounded by 50-cm-high walls made of plywood with a frontal glass wall, placed in a dimly illuminated room. The floor was covered with sawdust. The stimulus objects used in training and tests presented distinctive colors and shapes and were made of metal, glass, or plastic. In pilot experiments, all objects were behaviorally irrelevant and equally distinguished for the rats. Between trials, the objects were washed with a $70 \%$ ethanol solution. Exploration was defined as sniffing or touching the object with the nose and/or forepaws. Sitting on the object was not considered exploration. Training and tests procedures followed the general methods described in previous reports (Roesler et al. 2004a; de Lima et al. 2008; Reolon et al. 2011). Before training, the animals were habituated to the experimental arena by allowing them to freely explore it for $2 \mathrm{~min}$ in the empty arena. Twenty-four 
Amygdalar PDE4 and recognition memory persistence

hours after habituation, training was carried out by placing the rats in the open field containing two identical objects (objects A1 and A2) and leaving them to free explore for $5 \mathrm{~min}$. The objects were positioned in two adjacent corners, $9 \mathrm{~cm}$ from the walls. The rats were trained to a criterion of $30 \mathrm{sec}$ of total time exploring both objects. Five rats were excluded from the experiment because they did not accumulate $30 \mathrm{sec}$ of object exploration during the 5-min training. On retention test trials given 1,7 , and $14 \mathrm{~d}$ after training, each rat was placed in the open field for $5 \mathrm{~min}$ and left to freely explore. One of the objects (A) was exchanged for a novel object (B, C, or D). The new object was placed in the same location of objects as stimuli during the training trial. To reduce potential bias due to the preference of the animal for a specific location or object, all combinations and positions of objects were used in a balanced manner. Object exploration was measured by one experimenter blind to group treatment assignments. To measure retention, a discrimination index (DI) was calculated [DI $=\left(t_{\text {novel }}-t_{\text {familiar }}\right) /\left(t_{\text {novel }}+t_{\text {familiar }} \times\right.$ 100)] (Roozendaal et al. 2006, 2008).

Immediately, $1.5 \mathrm{~h}, 3 \mathrm{~h}$, or $6 \mathrm{~h}$ after training, a 30-gauge infusion cannula was fitted into the guide cannula. The tip of the infusion needle protruded $1.0 \mathrm{~mm}$ beyond the guide cannula and was aimed at the BLA. The animals received a bilateral $0.5-\mu \mathrm{L}$ infusion of vehicle (20\% dimethylsulfoxide [DMSO] in saline) or rolipram $(7.5 \mu \mathrm{g} /$ side dissolved in vehicle; Sigma-Aldrich) via the infusion cannula. The dose of rolipram was chosen on the basis of previous pilot experiments performed in our laboratory. Drug or vehicle was infused over a 30 -sec period. All behavioral sessions and drug infusions were performed during the light phase of the light/dark cycle.

Twenty-four hours after the 14 -d behavioral testing, a $0.5-\mu \mathrm{L}$ infusion of a $4 \%$ methylene blue solution was given into the BLA. Rats were killed by decapitation 15 min later for post-mortem verification of infusion placements based on the dye diffusion. The brains were removed and stored in 10\% formalin for at least $72 \mathrm{~h}$. The extension of the methylene blue dye was taken as indicative of diffusion of the drugs previously given to each rat (Roesler et al. 2003, 2004b). Rats with incorrect infusion placements were excluded from the analysis.

All data are expressed as the mean \pm SEM. Total exploration time of both objects during NOR training and retention test trials was compared using one-sample $t$-tests. The normality distribution was assessed using Shapiro-Wilk Statistics. A generalized linear model repeated-measures analysis (generalized estimating equations [GEE]) was used for comparisons between all variables and experiments. In all cases, if statistically significant interaction was found, additional pairwise comparisons were made using the Bonferroni post-hoc test. Normality distribution and identity as a link function was always used. In all cases, the significance of the effects was determined by Wald $\chi^{2}$ statistics; $P<0.05$ was considered to indicate statistical significance.

Table 1 summarizes the mean total time exploring both objects during NOR training and retention test trials. No significant differences were found between groups. Infusion of rolipram immediately after training did not significantly affect NOR retention measured 1, 7, or $14 \mathrm{~d}$ later (Fig. 1A), in spite of the apparent enhancement observed at 1 and $7 \mathrm{~d}$. There were no differences between groups in training or any of the retention test trials. Both groups showed a significantly higher discrimination index in the 24-h test trial compared to training (Wald $\chi^{2}(3)=130.886$, $P^{\prime} \mathrm{s}<0.001$ ) but not in tests carried out at 7 and $14 \mathrm{~d}$. The results indicate that PDE4 inhibition in the BLA shortly after training does not significantly affect NOR memory retention.

Intra-BLA rolipram infused $1.5 \mathrm{~h}$ after training did not affect NOR retention (Fig. 1B). There were no differences between groups in training or any of the retention test trials. Both groups showed a significantly higher discrimination index in the 24-h test trial compared to training (Wald $\chi^{2}(3)=111.294, \quad P^{\prime}$ s $<$ 0.001 ) but not in tests carried out at 7 and $14 \mathrm{~d}$. The results suggest that infusions of a PDE4 inhibitor into the BLA $1.5 \mathrm{~h}$ after training does not affect consolidation of NOR memory.

When given $3 \mathrm{~h}$ after training, rolipram enhanced NOR retention at all three retention test trials (Fig. 1C). The analysis revealed significant effects of treatment (Wald $\chi^{2}(1)=24.479, P<$ $0.001)$, trial day (Wald $\left.\chi^{2}(3)=76.686, P<0.001\right)$, and interaction treatment versus trial day (Wald $\chi^{2}(3)=10.932, P=0.012$ ). There were significant differences between rats treated with vehicle and rolipram in the retention test trials carried out 1,7 , and $14 \mathrm{~d}$ after training $(P<0.035 ; P<0.001 ; P<0.025)$ but not in the training trial. Comparisons between training and test trials in each group showed that rats given vehicle demonstrate significant memory retention $1 \mathrm{~d}(P=0.001)$ but not 7 or $14 \mathrm{~d}$ after training $\left(P^{\prime} \mathrm{s}=\right.$ 0.286 and 1.0, respectively). In contrast, rats infused with rolipram showed significantly higher discrimination indexes in all retention test trials (all $P^{\prime} s \leq 0.001$ ). The results indicate that intra-BLA rolipram at $3 \mathrm{~h}$ post-training enhances consolidation of NOR memory and, unexpectedly, promotes its persistence up to at least $14 \mathrm{~d}$ after training.

Rolipram administered $6 \mathrm{~h}$ after training had no effect on NOR retention. (Fig. 1D). There were no differences between groups in training or any of the retention test trials. Both groups showed a significantly higher discrimination index in the 24-h test trial compared to training (Wald $\chi^{2}(3)=35.145, P<0.01$ ), and rats treated with vehicle showed a higher discrimination index also in the 7-d test $(P<0.05)$, but there was no difference between training and the 14-d test in any of the groups. The results suggest that inhibition of amygdalar PDE $46 \mathrm{~h}$ after training does not significantly alter NOR memory.

Figure 2 shows a schematic drawing of the extent of the dye spread within the BLA of rats in which infusion placements were considered correct. Eleven rats were excluded because of incorrect infusion placements.

Because (1) all animals were trained to the same criterion of total object exploration, (2) no differences between groups in total exploration were observed in any of the trials, and (3) drug 

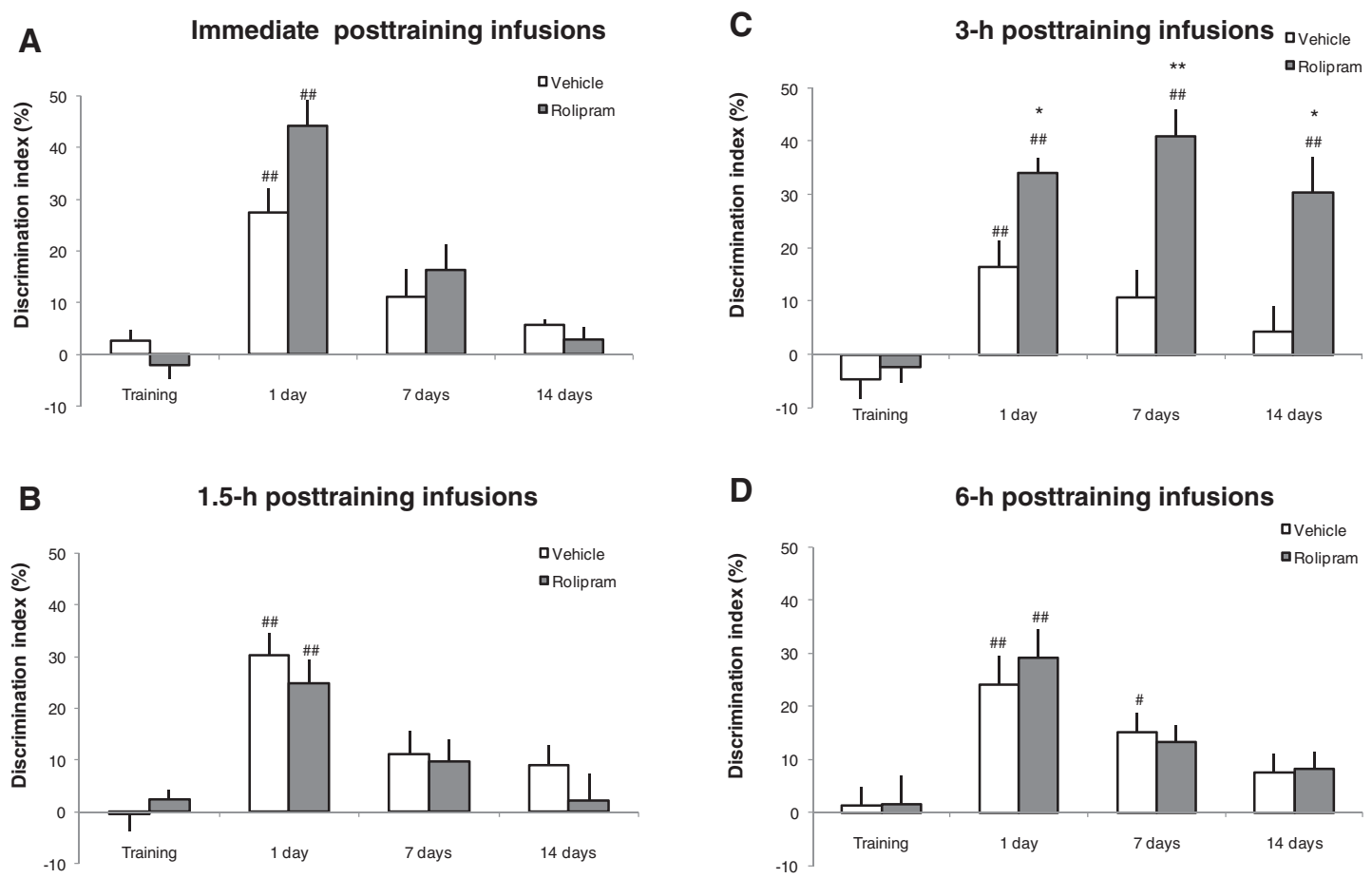

Figure 1. Recognition memory in rats infused with rolipram into the BLA at different time intervals after training. Rats were given NOR training and infused with vehicle or rolipram $(7.5 \mu \mathrm{g} /$ side) immediately $(A), 1.5 \mathrm{~h}(B), 3 \mathrm{~h}(C)$, or $6 \mathrm{~h}(D)$ after training. Retention test trials were carried out 1,7 , and $14 \mathrm{~d}$ later. Data are expressed as mean \pm SEM discrimination indexes; $n=8-12$ animals per group. $(*) P<0.05 ;(* *) P<0.01$ compared to control rats in the same trial; $(\#) P<0.05 ;\left(^{\# \#)} P<0.01\right.$ compared to the training trial within the same group.

infusions were given after training, the differences between rats treated with vehicle and rolipram observed are unlikely to be related to drug-induced alterations in acquisition, locomotion, motivation, sensorial function, or anxiety. Moreover, the possibility that rolipram infusions induced long-term effects that affected memory retrieval or nonspecific behavioral parameters during retention test trials can be ruled out because rolipram given at all post-training intervals except $3 \mathrm{~h}$ had no effect on test performance.

The main finding of the present study was that rolipram given into the BLA $3 \mathrm{~h}$ after training, but not at other post-training intervals, induced memory enhancement that persisted for at least $14 \mathrm{~d}$. The results indicate for the first time that inhibition of PDE4 in the BLA at a specific later time point after learning can induce a persistent enhancement of NOR memory.

Previous evidence has indicated a role for cAMP/PKA in the BLA in memory formation. Thus, intra-BLA infusion of a PKA inhibitor impairs fear conditioning (Schafe and LeDoux 2000) and blocks glucocorticoid-induced enhancement of fear memory (Roozendaal et al. 2002). Conversely, administration of a PKA activator into the BLA enhances memory for rewarding conditioning (Jentsch et al. 2002). A late phase (around $3 \mathrm{~h}$ after induction) of long-term potentiation (LTP) in the amygdala requires PKA as well as protein synthesis and mitogen-activated protein kinase (MAPK) and is regulated by agonists of $ß$-noradrenergic receptors (which act upstream of cAMP/PKA signaling) (Huang et al. 2000). Recent evidence suggests that PDE4 in the BLA interacts with $ß$-arrestin to negatively influence PKA activity and formation of memory for fear conditioning (Li et al. 2009). In studies using the NOR task, post-training pharmacological stimulation of noradrenergic receptors in the BLA enhanced 1-d retention of NOR (Roozendaal et al. 2008), and systemic injection of adrenaline immediately after training produced persistence of NOR memory at least up to $4 \mathrm{~d}$ (Dornelles et al. 2007). However, previous studies have not directly examined the role of PDE4 or other intracellular components of the cAMP/PKA/CREB pathway in the BLA in NOR memory. The finding that rolipram had an effect when given specifically $3 \mathrm{~h}$ after training is consistent with previous evidence that rolipram injected systemically at $3 \mathrm{~h}$, but not at 1 or $6 \mathrm{~h}$, after training enhanced the consolidation of NOR memory (Rutten et al. 2007). Our results suggest that stimulation of cAMP/PKA signaling in the BLA can significantly enhance memory formation at a time point in which PKA activity is required to promote enduring LTP in the amygdala and support the view that the BLA regulates the consolidation of memories for tasks involving low-arousing stimuli.

Although many aspects of the molecular basis of memory formation have been uncovered, much less is known about the mechanisms underlying long-term memory persistence, or maintenance, one of the main attributes of long-term memories (Dudai 2002; Bekinschtein et al. 2007). Evidence indicates that persistence of memory for a fear-motivated task can be selectively produced by administration, at a late interval ( $12 \mathrm{~h}$ ) after training, of brain-derived neurotrophic factor (BDNF) into the hippocampus and disrupted by hippocampal protein synthesis inhibition at the same time point (Bekinschtein et al. 2007, 2008). Since treatment with rolipram can increase BDNF levels in the rat brain (Nibuya et al. 1996; DeMarch et al. 2008), and the late phase of rolipram-induced LTP is dependent on BDNF (Navakkode and Korte 2012), an increase in amygdalar BDNF levels emerges as a candidate mechanism involved in mediating memory persistence induced by intra-BLA rolipram. Importantly, increases in amygdalar BDNF levels might be involved in mediating long-term memory persistence (Ou et al. 2010). Moreover, since pharmacological stimulation of the BLA results in increased expression of genes related to memory formation in other brain regions such as the hippocampus (McIntyre et al. 2005), it is also possible 


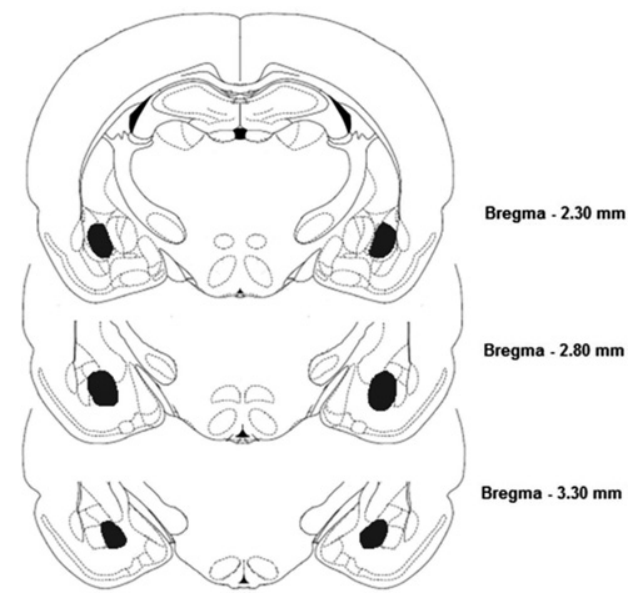

Figure 2. Infusion placements into the BLA. Schematic diagrams of coronal sections of the rat brain, adapted from the atlas of Paxinos and Watson (2007) with permission from Elsevier (C) 2007, depicting the diffusion of methylene blue in the BLA for rats included in the statistical analysis.

that intra-BLA rolipram leads to enhanced BDNF levels in other areas, which might be involved in mediating the enhanced NOR memory observed in the present study. Further experiments should address these possibilities.

In conclusion, the present findings provide the first evidence suggesting that PDE4 inhibition in the BLA after learning can enhance memory formation and produce long-term memory persistence. Experiments aimed at further characterizing the relationship between amygdalar cAMP/PKA/CREB signaling and memory persistence, as well as detailing the molecular mechanisms underlying the effects of PDE4 inhibition on long-term memory maintenance, are warranted.

\section{Acknowledgments}

This research was supported by the National Council for Scientific and Technological Development (CNPq) grant 303703/2009-1 to R.R., National Institute for Translational Medicine (INCT-TM), Coordination for the Improvement of Higher Education Personnel (CAPES; fellowships to M.B., P.F.C.J., and T.R.P.), and the HCPA Institutional Research Fund (FIPE/HCPA).

\section{References}

Barad M, Bourtchouladze R, Winder DG, Golan H, Kandel E. 1998. Rolipram, a type IV-specific phosphodiesterase inhibitor, facilitates the establishment of long-lasting long-term potentiation and improves memory. Proc Natl Acad Sci 95: 15020-15025.

Bekinschtein P, Cammarota M, Igaz LM, Bevilaqua LR, Izquierdo I, Medina JH. 2007. Persistence of long-term memory storage requires a late protein synthesis- and BDNF-dependent phase in the hippocampus. Neuron 53: 261-277.

Bekinschtein P, Cammarota M, Katche C, Slipczuk L, Rossato JI, Goldin A, Izquierdo I, Medina JH. 2008. BDNF is essential to promote persistence of long-term memory storage. Proc Natl Acad Sci 105: 2711-2716.

Bourtchouladze R, Lidge R, Catapano R, Stanley J, Gossweiler S, Romashko D, Scott R, Tully T. 2003. A mouse model of Rubinstein-Taybi syndrome: Defective long-term memory is ameliorated by inhibitors of phosphodiesterase 4. Proc Natl Acad Sci 100: $10518-10522$.

de Lima MN, Presti-Torres J, Garcia VA, Guimarães MR, Scalco FS, Roesler R, Schröder N. 2008. Amelioration of recognition memory impairment associated with iron loading or aging by the type 4-specific phosphodiesterase inhibitor rolipram in rats. Neuropharmacology 55: 788-792.

DeMarch Z, Giampà C, Patassini S, Bernardi G, Fusco FR. 2008. Beneficial effects of rolipram in the R6/2 mouse model of Huntington's disease. Neurobiol Dis 30: 375-387.
Dornelles A, de Lima MN, Grazziotin M, Presti-Torres J, Garcia VA, Scalco FS, Roesler R, Schröder N. 2007. Adrenergic enhancement of consolidation of object recognition memory. Neurobiol Learn Mem 88: $137-142$.

Dudai Y. 2002. Molecular bases of long-term memories: A question of persistence. Curr Opin Neurobiol 12: 211-216.

Huang YY, Martin KC, Kandel ER. 2000. Both protein kinase A and mitogen-activated protein kinase are required in the amygdala for the macromolecular synthesis-dependent late phase of long-term potentiation. J Neurosci 20: 6317-6325.

Jentsch JD, Olausson P, Nestler EJ, Taylor JR. 2002. Stimulation of protein kinase a activity in the rat amygdala enhances reward-related learning. Biol Psychiatry 52: 111-118.

Li Y, Li H, Liu X, Bao G, Tao Y, Wu Z, Xia P, Wu C, Li B, Ma L. 2009. Regulation of amygdalar PKA by $ß$-arrestin-2/phosphodiesterase- 4 complex is critical for fear conditioning. Proc Natl Acad Sci 106: 21918-21923.

McGaugh JL. 2004. The amygdala modulates the consolidation of memories of emotionally arousing experiences. Annu Rev Neurosci 27: $1-28$.

McIntyre CK, Miyashita T, Setlow B, Marjon KD, Steward O, Guzowski JF, McGaugh JL. 2005. Memory-influencing intra-basolateral amygdala drug infusions modulate expression of Arc protein in the hippocampus. Proc Natl Acad Sci 102: 10718-10723.

Navakkode S, Korte M. 2012. Cooperation between cholinergic and glutamatergic receptors are essential to induce BDNF-dependent long-lasting memory storage. Hippocampus 22: 335-346.

Nibuya M, Nestler EJ, Duman RS. 1996. Chronic antidepressant administration increases the expression of cAMP response element binding protein (CREB) in rat hippocampus. J Neurosci 16: 2365-2372.

Okuda S, Roozendaal B, McGaugh JL. 2004. Glucocorticoid effects on object recognition memory require training-associated emotional arousal. Proc Natl Acad Sci 101: 853-858.

Ou LC, Yeh SH, Gean PW. 2010. Late expression of brain-derived neurotrophic factor in the amygdala is required for persistence of fear memory. Neurobiol Learn Mem 93: 372-382.

Paxinos G, Watson C. 2007. The rat brain in stereotaxic coordinates, 6th ed., Academic Press, San Diego, CA.

Reolon GK, Maurmann N, Werenicz A, Garcia VA, Schröder N, Wood MA Roesler R. 2011. Posttraining systemic administration of the histone deacetylase inhibitor sodium butyrate ameliorates aging-related memory decline in rats. Behav Brain Res 221: 329-332.

Roesler R, Schröder N, Vianna MR, Quevedo J, Bromberg E, Kapczinski F, Ferreira MB. 2003. Differential involvement of hippocampal and amygdalar NMDA receptors in contextual and aversive aspects of inhibitory avoidance memory in rats. Brain Res 975: 207-213.

Roesler R, Kopschina MI, Rosa RM, Henriques JA, Souza DO, Schwartsmann G. 2004a. RC-3095, a bombesin/gastrin-releasing peptide receptor antagonist, impairs aversive but not recognition memory in rats. Eur J Pharmacol 486: 35-41.

Roesler R, Lessa D, Venturella R, Vianna MR, Luft T, Henriques JA, Izquierdo I, Schwartsmann G. 2004b. Bombesin/gastrin-releasing peptide receptors in the basolateral amygdala regulate memory consolidation. Eur J Neurosci 19: 1041-1045.

Roozendaal B, Quirarte GL, McGaugh JL. 2002. Glucocorticoids interact with the basolateral amygdala ß-adrenoceptor-cAMP/cAMP/PKA system in influencing memory consolidation. Eur J Neurosci 15: $553-560$.

Roozendaal B, Okuda S, Van der Zee EA, McGaugh JL. 2006. Glucocorticoid enhancement of memory requires arousal-induced noradrenergic activation in the basolateral amygdala. Proc Natl Acad Sci 103: $6741-6746$.

Roozendaal B, Castello NA, Vedana G, Barsegyan A, McGaugh JL. 2008. Noradrenergic activation of the basolateral amygdala modulates consolidation of object recognition memory. Neurobiol Learn Mem 90: $576-579$.

Rutten K, Prickaerts J, Blokland A. 2006. Rolipram reverses scopolamine-induced and time-dependent memory deficits in object recognition by different mechanisms of action. Neurobiol Learn Mem 85: $132-138$.

Rutten K, Prickaerts J, Hendrix M, van der Staay FJ, Sik A, Blokland A. 2007. Time-dependent involvement of cAMP and cGMP in consolidation of object memory: Studies using selective phosphodiesterase type 2, 4, and 5 inhibitors. Eur J Pharmacol 558: 107-112.

Schafe GE, LeDoux JE. 2000. Memory consolidation of auditory Pavlovian fear conditioning requires protein synthesis and protein kinase $\mathrm{A}$ in the amygdala. J Neurosci 20: RC96.

Tully T, Bourtchouladze R, Scott R, Tallman J. 2003. Targeting the CREB pathway for memory enhancers. Nat Rev Drug Discov 2: 267-277.

Received May 8, 2012; accepted in revised form May 30, 2012. 


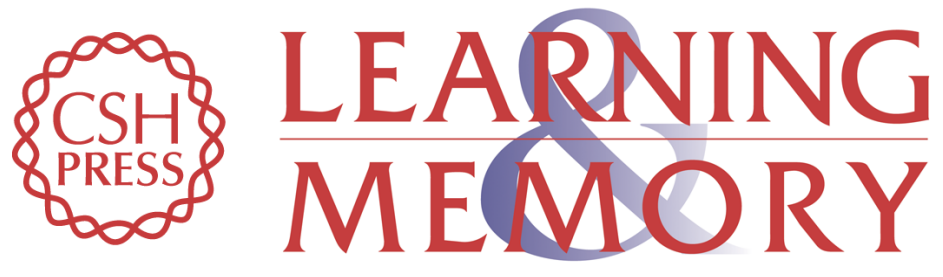

\section{Administration of the phosphodiesterase type 4 inhibitor rolipram into the amygdala at a specific time interval after learning increases recognition memory persistence}

Aline Werenicz, Raissa R. Christoff, Martina Blank, et al.

Learn. Mem. 2012, 19:

Access the most recent version at doi:10.1101//m.026997.112

References This article cites 28 articles, 10 of which can be accessed free at: http://learnmem.cshlp.org/content/19/10/495.full.html\#ref-list-1

License

Email Alerting

Receive free email alerts when new articles cite this article - sign up in the box at the Service top right corner of the article or click here. 